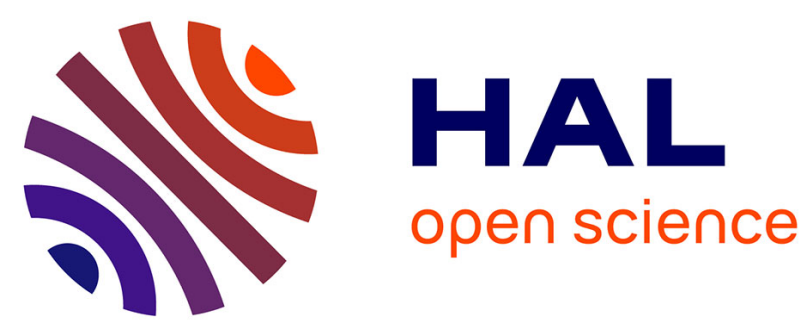

\title{
Service Personalization Requirements for Elderly Care in a Collaborative Environment
}

\author{
Thais Andrea Baldissera, Luis M. Camarinha-Matos, Cristiano De Faveri
}

\section{To cite this version:}

Thais Andrea Baldissera, Luis M. Camarinha-Matos, Cristiano De Faveri. Service Personalization Requirements for Elderly Care in a Collaborative Environment. 8th Doctoral Conference on Computing, Electrical and Industrial Systems (DoCEIS), May 2017, Costa de Caparica, Portugal. pp.20-28, 10.1007/978-3-319-56077-9_2 . hal-01629600

\section{HAL Id: hal-01629600 https://hal.inria.fr/hal-01629600}

Submitted on 6 Nov 2017

HAL is a multi-disciplinary open access archive for the deposit and dissemination of scientific research documents, whether they are published or not. The documents may come from teaching and research institutions in France or abroad, or from public or private research centers.
L'archive ouverte pluridisciplinaire HAL, est destinée au dépôt et à la diffusion de documents scientifiques de niveau recherche, publiés ou non, émanant des établissements d'enseignement et de recherche français ou étrangers, des laboratoires publics ou privés. 


\title{
Service Personalization Requirements for Elderly Care in a Collaborative Environment
}

\author{
Thais Andrea Baldissera ${ }^{1}$, Luis M. Camarinha-Matos ${ }^{1}$, Cristiano De Faveri ${ }^{1}$ \\ Centre Technology and Systems, UNINOVA \\ NOVA University of Lisbon \\ Caparica, Portugal \\ tab@uninova.pt,cam@uninova.pt, c.faveri@campus.fct.unl.pt
}

\begin{abstract}
In diverse sectors companies collaborate to offer integrated usercentric services to obtain competitive advantage. However, regarding elderly care, services are typically isolated, and mostly provided by a single provider. Moreover, there is a need to personalize services in respect of the individuality of each senior and making these services evolve according to the lifestyle and necessities of the person. In this context, the concept of Elderly Care Ecosystem (ECE) emerges as a computer-based collaborative environment that promotes the integration of distinct services and providers. ECEs are complex systems that demand a clear description of their requirements, especially of those related to personalization of services. In this paper, we describe a set of core requirements and challenges for designing personalized services in an elderly care ecosystem. In particular, our contributions are: the identification of the main stakeholders of an ECE, the requirements to build a persona profile in ECE, and a reference requirements model based on $i^{*}$ for service personalization in ECE.
\end{abstract}

Keywords: Collaborative Business Service, service personalization, requirements, elderly care, aging.

\section{Introduction}

Aging of the global population represents one of the most significant demographic changes in the humanity history. The increase of the average life expectancy associated to the declination of fertility led to the growing of the median age of the population, being expected that those over 80 years will exceed the young in 2050 [1]. This aging process is responsible for changes at various levels, which may impact a number of different aspects of older adults' lives and limit the extent to which they are able to perform certain activities. This reality reflects the need for adaptations in the society to provide better healthcare and inclusion solutions for elderly people.

Research and development as well as industry practice in elderly care services has conventionally dedicated on the development of isolated services, contemplating only a single service provider and often showing an extreme focused on technology. Also services delivery often does not fully cover customers care needs and remain static until there is a customer request for change. As it is well-known in other sectors, to 
answer current demanding market challenges, organizations must collaborate to overcome their weaknesses and strengthen their expertise, to offer better integrated services, focusing on user-centric services and gaining competitive advantage [2]. Furthermore, in the elderly care context, there is a need for personalized services that respect the individuality of each senior and cope with the evolution of needs, since the senior's life context changes along the aging process [3].

In order to emphasize this perspective, the term Elderly Care Ecosystem (ECE) was proposed in [1]. In particular, the ECE is aimed at enabling the integration of different services from distinct providers. In this way, care and assistance services for elderly can be seen as "the result of collaboration among various stakeholders, including local communities, governmental institutions, professionals, family and caregivers, and thus require a supporting collaboration environment" [1].

As such, this research aims at contributing to a more effective provision of services for elderly care in the context of collaborative networks. The main research question addressed by this work is: "How to provide personalized care services for elderly?" The pursued hypothesis is: "Effective and reliable personalized services for elderly care can be provided if a suitable set of multi-provider business services is composed and integrated in the context of a collaborative network environment".

The first step to design such a system is to understand the domain of the problem we want to solve. This is covered during the first stages of requirements engineering, where domain analysis and elicitation are typical activities. These steps are highly intertwined and seek at grasping the system as-is, identifying problems and opportunities, discovering the real needs of the stakeholders with respect to the ecosystem, and exploring alternative ways to address those needs [4]. In this paper, we highlight requirements for elderly care ecosystems, including the set of stakeholders and their interactions.

The relationship to smart system is presented in Section 2. Background and approach paradigm (Section 3) support the provision of integrated services and help service providers to acquire agility and better survive in market. The Elderly Care Ecosystem Description (Section 4) introduces the environment and potential challenges in this domain. In Section 5, the ecosystem stakeholders' identification and relations between them are described as well as the elderly care ecosystem characterization and business service targeting. Finally, we conclude in Section 6 identifying the future work.

\section{Relationship to Smart Systems}

Recent trends in the development of smart environments and services for humancentered applications point to personalized care and improved quality of life [5]. The elderly community represents a relevant portion of the world population and tends to be more active and independent, assisted by emergent technologies, such as those based on the Internet of Things, embedded and wearable systems as well as cloud computing. The inclusion of progressive levels of intelligence in these systems is likely to provide better support to these users and increase their quality of life. 
A practical application of smart system for elderly care is exemplified by the Susan's illustrative scenario in Fig. 1. Susan is 82 years old, lives alone, but has a very active life. She likes to go out with her friends, attends social events, and does social work. She takes care of her health and preserves natural resources as much as she can. She has a SPA device (Smart Personal Assistant) which interacts with her in different moments of Susan's life and guides her steps in order to respect her lifestyle and intentions.

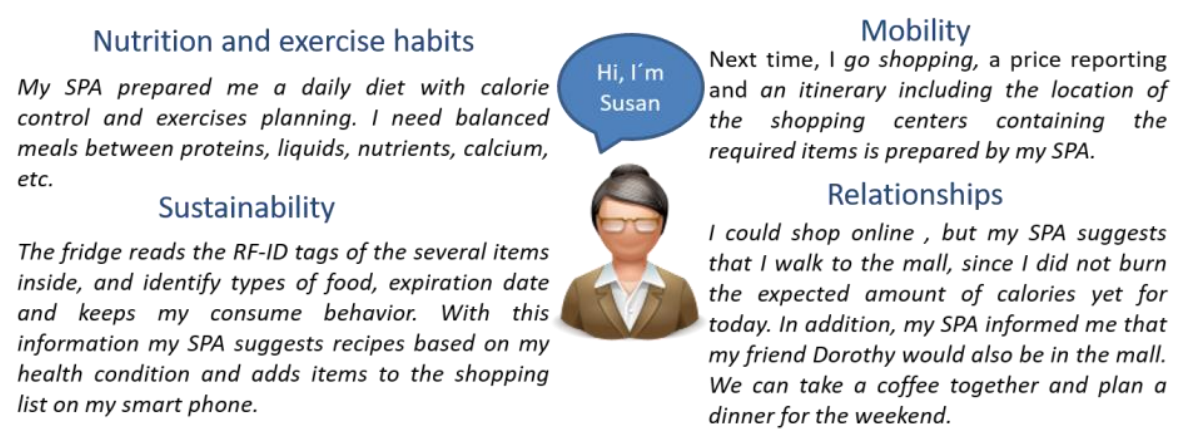

Fig. 1 Susan's Illustrative Scenario

\section{Trends in Elderly Care Ecosystem Design}

Our focus is to describe requirements for the design and construction of an elderly care ecosystem that considers two main aspects: personalization and evolution of services. Both aspects depend on a set of data about customers, providers, regulations and the network itself, to determine a ranking of potential services for each customer. This ranking considers individual customer's needs and a set of criteria that suggests the best services in a given moment.

Domain understanding and requirements elicitation are typically performed by studying key documents, investigating similar ecosystems and interviewing or observing the identified stakeholders. In the elderly care domain, potential ECE stakeholders include professional entities and care people, suppliers and support entities, and customers. We analyzed a number of research projects on ICT and aging as part of the elicitation process. These projects have been developed since 2001 as part of ICT and Aging agenda of European framework programs. For instance, AMIGO$^{1}$ Project "Ambient Intelligence for the Networked Home Environment" - was one of the first addressing collaborative providers with integrated services in 2004. EMOTIONAAL ${ }^{2}$ project effectively focused on services delivered through various providers addressing

\footnotetext{
${ }^{1} \mathrm{ftp} / / / \mathrm{ftp}$. cordis.europa.eu/pub/ist/docs/directorate_d/st-ds/amigo-project-story_en.pdf

${ }^{2} \mathrm{http}: / /$ www.aal-europe.eu/projects/emotionaal/
} 
the healthcare-concept for elderly persons in rural areas in Europe. ePAL project (Extending Professional Active Life) developed a strategic research roadmap focused on innovative collaborative solutions and ensuring a balanced postretirement life-style.

BRAID project - "Bridging Research in Ageing and ICT Development" [6] introduced four perspectives or life settings (adopted in our work): (i) independent living: how technology can assist in normal daily life activities, e.g., tasks at home, mobility, safety, agenda management (memory help), etc.; (ii) health and care in life: how technology can assist in health monitoring, disease prevention, and compensation for disabilities; (iii) occupation in life: how technology can support the continuation of professional activities along the ageing process; (iv) recreation in life: how technology can facilitate socialization and participation in leisure activities. Since 2010, 21 other relevant projects were identified, which focused on some form of collaborative providers. Out of these projects, 18 delivered atomics services and 3 developed integrated services, all with larger focus on independent living. In particular, Ambient Assistance Living for All - AAL4ALL ${ }^{3}$ project conducted a field survey aimed at both characterizing current users of AAL technologies and understanding how potential future users feel about and are willing to use this type of technology.

\section{Requirements of ECE}

\subsection{ECE Stakeholders}

An ECE model include many components, including customers (seniors) and their wants and limitations, care services, and service provision entities [1]. The organization of this ecosystem model is proposed per four environments: customer, care needs, service, and service providers. Customer relates to relevant information about elderly as an entity within the ECE. Care need represents the main necessities of individuals within the elderly domain. Service is provided by service providers, and it represents a care service available within the ecosystem.

A detailed customer's profile, including historical record, is fundamental to identify the best option (ranking) of care services that attends his/her individual and specific needs. In addition, context analysis, considering available stakeholders and devices, can provide a valuable contribution for potential service rating. We identified the following environments in ECE:

A. Customer Environment, representing the elderly customers and their ambient and context. It includes:

- Elderly. In ECE, a customer is characterized by typical personal attributes such as name, surname, nickname, gender, birth date, contact, marital status, etc. Geographical location is highlighted for guiding regional preferences and service coverage.

${ }^{3} \mathrm{http}: / /$ www.aal4all.org/ 
- Elderly Family, Caregivers and Friends. Many people live with their family when they begin to lose capabilities, representing the traditional way to deal with aging but that requires intense care from family. Therefore, other relevant information is about caregivers, family members and relatives who are responsible for them. Relatives need to actively participate in the aging process and support the elderly.

- Applications and Devices. Software and hardware which interact with the elderly leading to context-aware systems. Sensorial device information contributes to frequent contextual analysis and to input for efficient service adaptation to current elderly context.

B. Intermediaries Environment, representing people or organizations whose main function is to provide opportunities for the relation between customers and service providers. It includes:

- Broker. An entity responsible to receive customer's request and identify the services available to attend the request.

- Professional stakeholders. Representing medical professionals, care homes, housing associations, local communities, etc. These stakeholders are particularly associated with those individuals who live by themselves but require professional care to assist them.

- Suppliers. They are enterprises with a business in tele-medicine or tele-care, providers of the ICT infrastructures - networks and applications, enterprises of hardware and software and/or service provision, etc.

- Regulation and Support entities. Examples include policy-makers, social insurance companies, public administrations, government roles, standardization organizations, civil society organizations, media services providers, etc.

C. Organization Environment, representing the care provision stakeholders with the goal to provide care and assistance services. It includes:

- Single Entity, representing an individual service provider.

- Virtual Organization, representing a set of collaborative services providers working together for a common goal. A single provider probably cannot properly fulfill all needs of a customer, if it operates alone. When a situation of tailored care arises, service providers can organize themselves in a partnership and deliver an integrated service.

\subsection{ECE Characterization}

In this section, we characterize the envisioned Elderly Collaborative Ecosystem and describe the requirements of the personalization process. In the elderly care domain, 
personalization involves the analysis of the senior's life context and can be achieved by composing a set of specific business services. We assume a data-rich environment in which data can be acquired via specific sensors and devices. In an automated environment (fully or semi), the characteristics and composition of the services set can evolve. As a result, a new service can start, a current service may evolve, or a service can be disabled or excluded from the customer's portfolio. For each new context change, the responsible care and assistance provider organization shall analyze the situation (in collaboration with all relevant stakeholders), and evolve the service to fit that context.

\subsection{Service Personalization and Evolution}

The main requirements for a service personalization and evolution are synthetized in Fig. 2. A goal-oriented approach is used to express a strategic dependency model using i* language [7], which allows to describe goals, softgoals, tasks, resources, and dependencies among multiple actors. The main goal of the model is to support a middle layer for service provision between the Service Provider Environment (actor Service Providers) and the Elderly Living Environment (actor Customer).

The Broker is responsible for collecting information about ECE costumer's care and assistance service requirements (through questionnaires, identification of similarities with other customers, etc.) and verifying if an adequate service description is already available in the service catalogue, as expressed in the tasks within the Broker boundary (Manage service requests info and its decompositions). If the service is available in the ECE, the goal Request/subscribe an existing service can be achieved. If it is an undefined service, the Broker is responsible for launching a new care and assistance service design, involving the relevant stakeholders along with the Service Composition activity [8]. This is expressed in the goal Request a desired service.

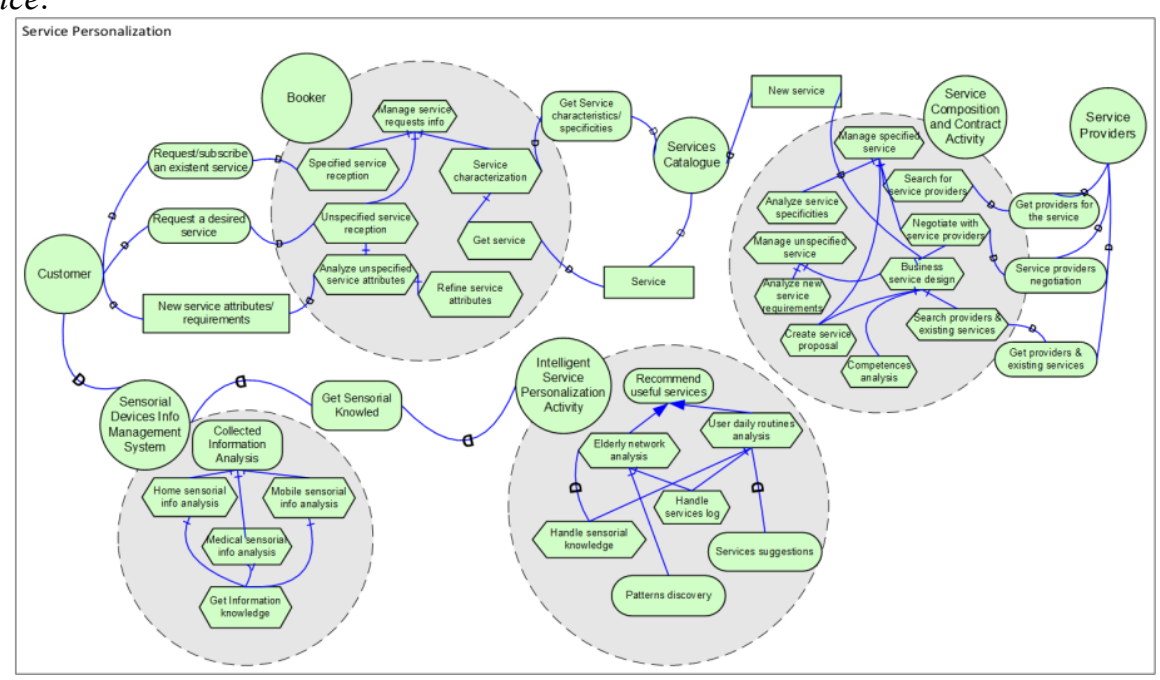

Fig. 2. i* Rationale Strategic Model for the Service Personalization 
The Sensorial Devices Information Management System gets information from the multiple sources and analyzes these data. This result is sent to the Intelligent Service Personalization Activity which, by using relevant information, is able to recommend and/or suggest changes in current services for each ECE customer. Customer profile is required to be constantly updated to reflect most fresh information about a person. Types of input information include: sensorial information, essentially for contextawareness; relevant information from the ECE customer, to verify if additional services are necessary; analysis of the ECE customer's daily habits to recommend or suggest a care and assistance services adapted to the corresponding routines; and analysis of ECE to discover new patterns in ECE customer's behavior. A challenge here is to guarantee privacy of users and non-intrusiveness.

\subsection{Business Service Targeting}

Service proposition is a key component of the ECE. It is responsible for selecting and ranking a list of services based on the customer profiles and care needs. We highlight some key aspects of service proposition requirements and challenges that should be overcome during the design and implementation of an ECE. It is not our intention to present a comprehensive list of concerns (e.g. security and privacy, cold start phenomenon, fault tolerance, etc.). Instead, we describe concerns we understand are those more critical for designing a service recommendation feature in the context of the ECE.

- Service mapping. Mapping customer's need and potential services constitutes one of the major challenges when designing personalized services in the ECE. There is a multitude of parameters that may be considered to select a set of services in the ecosystem. Services can require distinct data to cover a certain care need, thus, the matching process should be flexible enough to connect both sides (customer needs and services). In this sense, it is necessary to identify a common "language" that maps them to a taxonomy of services and care needs. A partial example of such taxonomy is shown in Fig. 3. For instance, a service can be linked to Remote monitoring, which means it attends care needs related to Follow-up monitoring and Regular monitoring. However, a care need linked to Medication assistance is not matched by a service that is assigned to Health life style assistance.

- Ranking. Once a list of potential services is built, there is a need to rank relevant services to be suggested to the customer. This is a classical problem in recommendation systems that depend on a number of parameters to determine the most relevant outcome for a particular customer.

- Scalability. As the amount of providers and customers grow, selecting services in response to new customer's state can be computationally infeasible. There is a need to optimize the searching for potential services, while keeping the recommendation list relevant for a particular customer.

- Timing. As a customer may require several services that require multiple sensors to acquire proper data, determining the time interval of sensing remains a challenge. 
If this time is too short, the ECE can suffer for a lack of resources. On the other hand, if this time is too long, the ECE may be inefficient to determine a service evolution.

- Accuracy prediction. Sensors data can be incomplete, due to failures on sensing devices, noise in the communication, among other factors. Under this situation, a recommendation function demands predictive mechanisms to keep ECE operational.

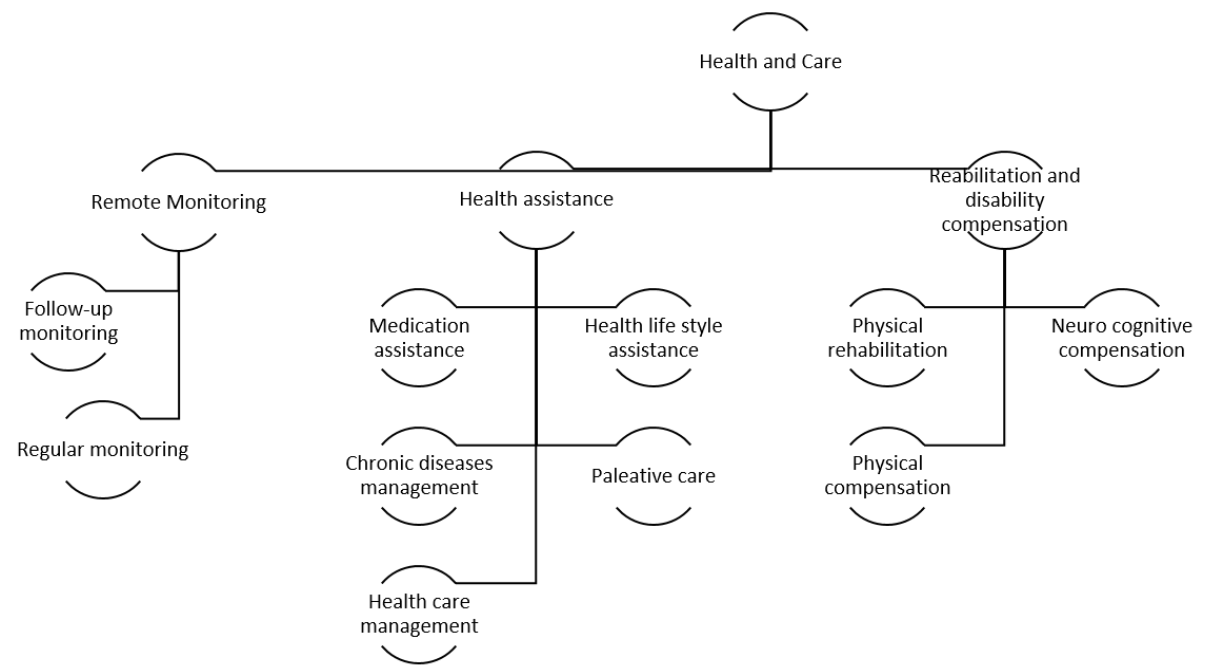

Fig. 3. Health and Care in life taxonomy partial example.

A preliminary approach to service recommendation and composition, following a set of service adherence criteria based on a fuzzy causal network for rating care services, was presented in [9]. This system is now being refined, taking into account the identified requirements. An overview of its main elements is shown in Fig. 4. 


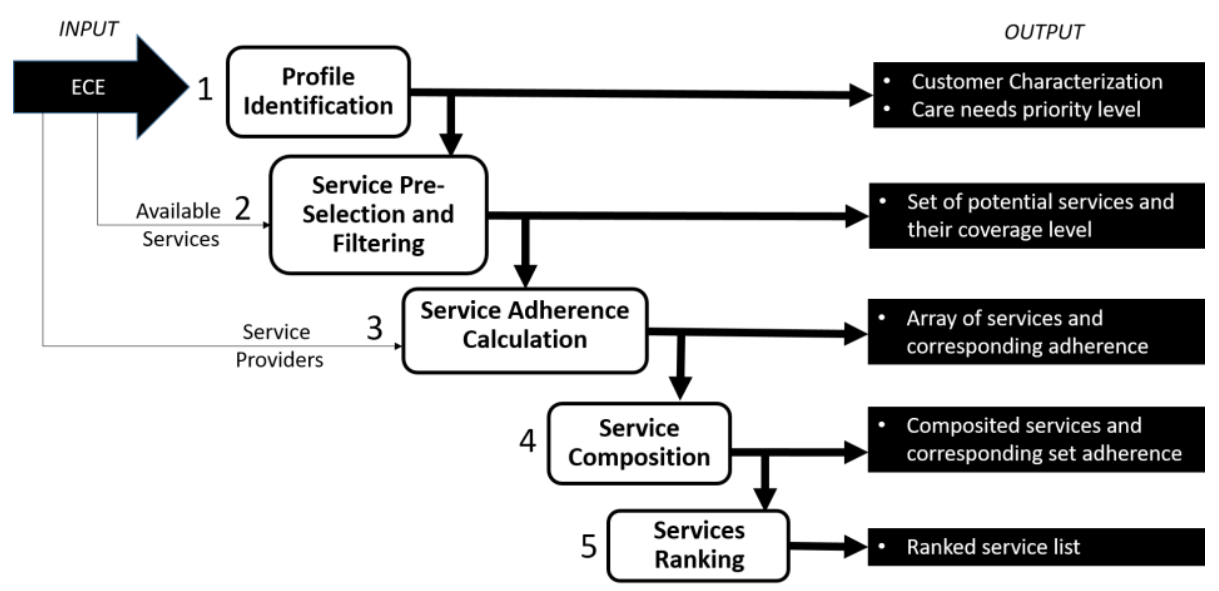

Fig. 4. Service recommendation and composition process on ECE

\section{Conclusions and Future Work}

Elderly Care Ecosystems can play an important role in delivering collaborative and personalized services for the elderly community. ECE represents a complex system that demands a careful identification and analysis of requirements, such that more useful systems can be built. With this purpose, we presented a set of core requirements for service personalization in ECE and a set of relevant challenges regarding service recommendation, as part of a collaborative environment for elderly care. As part of our future work, we are refining the design of a multi-criteria mechanism to support the selection and ranking process of personalized services.

Acknowledgment. This work has been funded in part by the Center of Technology and Systems and the Portuguese FCT-PEST program UID/EEA/00066/2013 (Impactor project), and by the Ciência Sem Fronteiras program and Erasmus Mundi project (Brazil and European Commission).

\section{References}

1. Baldissera, T. A., Camarinha-Matos, L. M. (2016). Towards a Collaborative Business Ecosystem for Elderly Care. In M. L. Camarinha-Matos, A. J. Falcão, N. Vafaei \& S. Najdi (Eds.), Technological Innovation for Cyber-Physical Systems: 7th IFIP WG 5.5/SOCOLNET Advanced Doctoral Conference on Computing, Electrical and Industrial Systems, DoCEIS 2016, Costa de Caparica, Portugal, April 11-13, 2016, Proceedings (pp. 24-34). Springer International Publishing.

2. Camarinha-Matos, L. M., Rosas, J., Oliveira, A. I., Ferrada, F. (2015). Care services ecosystem for ambient assisted living. Enterprise Information Systems, 9(5-6), 607-633. 
3. O’Grady, M. J., Muldoon, C., Dragone, M., Tynan, R., O’Hare, G. M. (2010). Towards evolutionary ambient assisted living systems. Journal of Ambient Intelligence and Humanized Computing, 1(1), 15-29.

4. Van Lamsweerde, A. (2009). Requirements engineering: from system goals to UML models to software specifications: Wiley Publishing.

5. Moar, J. (2015). Smart Wearable Devices: Market Trends \& Competitive Landscape 20152020. Retrieved 05/01/2017, from http://www.juniperresearch.com/researchstore/deviceswearables/smart-wearables/market-trends-competitive-landscape

6. Camarinha-Matos, L. M., Afsarmanesh, H., Ferrada, F., Oliveira, A. I., Rosas, J. (2013). A comprehensive research roadmap for ICT and ageing. Studies in Informatics and Control, 22(3), 233-254.

7. Yu, E., Giorgini, P., Maiden, N., Mylopoulos, J. (2010). Social Modeling for Requirements Engineering (Vol. 1). Toronto, Canada: The MIT Press.

8. Camarinha-Matos, L. M., Afsarmanesh, H., Oliveira, A. I., \& Ferrada, F. (2013). Collaborative Business Services Provision. Paper presented at the ICEIS'13 - 15th International Conference on Enterprise Information Systems, Angers, France, 382-392.

9. Baldissera, T. A., Camarinha-Matos, L. M. (2016). Services Personalization Approach for a Collaborative Care Ecosystem. In H. Afsarmanesh, M. L. Camarinha-Matos \& A. Lucas Soares (Eds.), Collaboration in a Hyperconnected World: 17th IFIP WG 5.5 Working Conference on Virtual Enterprises, PRO-VE 2016, Porto, Portugal, October 3-5, 2016, Proceedings (pp. 443-456). Springer International Publishing. 